\title{
EDITORIAL
}

\section{In This Issue: Critical Topics in Primary Care}

\author{
Robin S. Gotler, MA, Reflections Editor/Editorial Coordinator \\ Ann Fam Med 2009;7:386-387. doi:10.1370/afm.987.
}

I $\mathrm{n}$ this issue of the Annals, researchers shed light on some of the most pressing issues facing primary care today: the impact of health insurance (or lack thereof), the intricacies of screening for disease, and the vital role of social and cultural factors in health care.

\section{LIMITS AND POTENTIAL OF UNIVERSAL HEALTH COVERAGE}

In a study set in Ontario, Canada, Glazier et al investigate the extent to which universal coverage of physician services reduces socioeconomic disparities in care. ${ }^{1}$ They find that although income is not associated with inequities in physician contact or frequency of visits, higher education is inversely associated with frequent visits to primary care and directly associated with visits to specialty care. In the Ontario system, universal insurance appears to be successful in achieving income equity in physician visits, but it does not eliminate education-related differences in specialist care.

A study by DeVoe et al helps make the case for universal health insurance coverage in the United States and contributes to the hotly debated issue of health system reform. ${ }^{2}$ The study examines the relationship between parental insurance coverage and children's access to care and finds that, when parents lack health insurance, their children are more likely to go without necessary medical and preventive services. As the authors point out, "If the current trend continues, the majority of US children will soon live in families with discordant and disrupted patterns of family health insurance." 2

One of the missing links in US health policy is an integrative perspective. The fourth in a series of editorials on generalism presents a framework for integrating health care components, an approach that can foster the development of comprehensive, relationshipcentered systems of care. ${ }^{3}$

\section{DIABETES, DEPRESSION, AND RISK}

Two articles in this issue address the challenges of screening for diabetes and depression. In an investigation of the yield of opportunistic targeted screening for diabetes in primary care, Klein Woolthuis et al find that the strongest predictor of undiagnosed diabetes is obesity. ${ }^{4}$ When targeting high-risk individuals, the number needed to screen was 37 (vs 233 for low-risk individuals). In a systematic review of an at-risk population, Reuland et al conclude that there is fair evidence to support the use of 5 commonly used instruments to accurately screen for depression in Spanish-speaking patients. ${ }^{5}$

Lin et al examine the association of diabetes with depression and other causes of mortality. They find that patients with both diabetes and depression have higher mortality risks beyond cardiovascular deaths. ${ }^{6}$

\section{A SOCIAL AND CULTURAL LENS}

Studies in this issue focus a social and cultural lens on issues of health and health care. Mainous et al find that antibiotics are widely available on the Internet without prescription. ${ }^{7}$ Given the unregulated nature of the Internet, these findings may have serious implications for patient health, quality of care, and efforts to reduce antibiotic resistance.

A randomized controlled trial by Barnet et al shows that a community-based home visiting intervention is effective in reducing rapid repeat births among lowincome teenaged mothers. ${ }^{8}$ This innovative approach uses a computer-assisted motivational intervention conducted by paraprofessionals in community settings.

\section{REALITIES OF CLINICAL PRACTICE}

Research from the Netherlands provides insights into clinical practice. In a study of 21 Dutch general practices, diagnostic category, duration of complaints, and functional limitations are key variables in management 
decisions for nontraumatic complaints of arm, neck, and shoulder. ${ }^{9}$

In a poignant essay, Blevins reminds us that research is a valuable but distant source of knowledge. When it comes to clinical practice, patients remain our greatest teachers. ${ }^{10}$

To read or post commentaries in response to this article, see it online at http://www.annfammed.org/cgi/content/full/7/5/386.

\section{References}

1. Glazier RH, Agha MM, Moineddin R, Sibley LM. Universal health insurance and equity in primary care and specialist office visits: a population-based study. Ann Fam Med. 2009;7(5):396-405.

2. DeVoe JE, Tillotson CJ, Wallace LS. Children's receipt of health care services and family health insurance patterns. Ann Fam Med. 2009;7(5):406-413

3. Stange KC. A science of connectedness. Ann Fam Med. 2009;7(5): 387-395.
4. Klein Woolthuis EP, de Grauw WJC, van Gerwen WHEM, et al. Yield of opportunistic targeted screening for type 2 diabetes in primary care: the Diabscreen study. Ann Fam Med. 2009;7(5):422-430.

5. Reuland DS, Cherrington A, Watkins GS, Bradford DW, Blanco RA, Gaynes BN. Diagnostic accuracy of Spanish language depressionscreening instruments. Ann Fam Med. 2009;7(5):455-462.

6. Lin EHB, Heckbert SR, Rutter CM, et al. Depression and increased mortality in diabetes: unexpected causes of death. Ann Fam Med. 2009;7(5):414-421.

7. Mainous AG III, Everett CJ, Post RE, Diaz VA, Hueston WJ. Availability of antibiotics for purchase without a prescription on the Internet. Ann Fam Med. 2009;7(5):431-435.

8. Barnet B, Liu J, DeVoe M, Dugan AK, Gold MA. Motivational intervention to reduce rapid subsequent birth of adolescent mothers: a community-based randomized trial. Ann Fam Med. 2009;7(5):436-445.

9. Feleus A, Bierma-Zeinstra SMA, Bernsen RMD, Miedema HS, Verhaar JAN, Koes BW. Management decisions in nontraumatic complaints of arm, neck, and shoulder in general practice. Ann Fam Med. 2009;7(5):446-454.

10. Blevins SM. Gazing at the future. Ann Fam Med. 2009;7(5):463-464.

\title{
EDITORIAL
}

\section{A Science of Connectedness}

\author{
Kurt C. Stange, $M D, P b D$, Editor \\ Ann Fam Med 2009;7:387-395. doi:10.1370/afm.990.
}

$\mathrm{H}$ ow can health care reform approach the holy trinity of equitable access, controlled costs, and high value?

How can the sweet spot be found in the midst of the politically charged and personally wrenching trade-offs? The sweet spot is where increasing access to health care creates a sense of commonality rather than division, where choices about the use of services are prioritized based on personalized knowledge rather than crude administrative rationing, and where cost control happens in ways that add value and diminish waste.

Previously, this editorial series examined the problem of fragmentation, ${ }^{1}$ a generalist solution, ${ }^{2}$ and the paradox of primary care. ${ }^{3}$ This fourth piece in the series explores an integrated way of understanding how the components of health care can work together to balance access, cost, and quality. This framework is not so much a cookbook as a way of making sense of the current situation and a guidepost for traveling hopefully to a better future.

\section{CONNECTING THE PARTS AND THE WHOLES}

In the summer of 1968 in the Austrian mountain hamlet of Alpbach, author Arthur Koestler convened a scientific symposium intended to challenge "the insufficient emancipation of the life sciences from the mechanistic concepts of nineteenth-century physics and the resulting crudely reductionist philosophy." ${ }^{4(\mathrm{p} 2)}$ The participants' task then is highly relevant to health care today, which is stuck in a similarly old-fashioned worldview that does not fit the reality of how health is lost and created, and how the pieces of health care evolve together to create value.

At the Alpbach Symposium, scientists from a variety of fields, including biologist Paul Weiss, biochemist Holger Hydén, developmental psychologists Jean Piaget and Bärbell Inhelder, psychopharmacologist Seymour Kety, humanist psychiatrist Viktor Frankl, evolutionary biologist C. H. Waddington, and the father of general systems theory, Ludwig von Bertalanffy, presented data from vastly diverse experiments and observational studies. The common thread-actually 